\title{
Testing Informational Efficiency in the EU ETS
}

\author{
Sebastian Goers \\ Energy Institute at the Johannes Kepler University, Linz, Austria \\ Department of Energy Economics \\ e-mail: goers@energieinstitut-linz.at
}

Cite as: Goers, S., Testing Informational Efficiency in the EU ETS, J. sustain. dev. energy water environ. syst., 2(4), pp 319-330, 2014, DOI: http://dx.doi.org/10.13044/j.sdewes.2014.02.0026

\begin{abstract}
The paper deals with the analysis of informational efficiency of the European emissions trading scheme (EU ETS) with the goal of stating whether or not the system has been able to achieve its proclaimed cost-efficiency within the first two trading periods. The efficient market hypothesis suggests that profiting from predicting price behaviour is difficult as the market price should incorporate all available information at any time. I analyse the EU emission market to see if it shows evidence of the weak form of informational efficiency. In order to analyse the weak form of informational efficiency assessments I analyse random walk properties such as, the unit root, autocorrelation and variance ratio tests. The results reveal the existence of informational efficiency only in the second trading period.
\end{abstract}

\section{KEYWORDS}

European emissions trading scheme, Informational efficiency, Efficient market hypothesis, Random walk theory, Unit root tests, Autocorrelation, Variance ratio tests.

\section{INTRODUCTION}

The main objective of emissions trading is to offer a cost-efficient market-based instrument for emission mitigation. Cost-efficiency of the system induces that the predefined emission target is achieved by minimum costs and involves a well-functioning and established market, i.e. a market that provides informational efficiency. Informational efficiency implies that allowance prices display all significant information, market participants understand the realization of the emissions price and a forecast of future emissions prices, and hence earning above average returns is impossible. In the case of inefficient markets, due to transaction costs, incomplete information and heterogeneous expectations of market participants, which do not allow for forecasting future carbon price, an intensification of regulation in order to increase information flows and decrease market manipulation will be necessary. The fact that the European emissions trading scheme (EU ETS) finished the second trading phase at the end of 2012 allows for a complete investigation of the system's informational efficiency during the first two trading periods and to evaluate the scheme's effectiveness and efficiency during this timeframe.

The remainder of this paper is organized as follows. After some background information on the EU ETS and a brief review of econometric literature on the (informational) efficiency of the scheme in the introductory section, the second section explains theoretically the efficient market hypothesis and its connection to random walk theory. Thirdly, the statistical methodology and the data are described. The fourth section presents the results and the final section summarises the main findings. 


\section{Emissions trading in Europe}

As an important player in the Kyoto and post-Kyoto process, the European Union (EU) itself decided to base its climate policy primarily on emission trading by the adoption of Directive 2003/87/EC establishing a scheme for greenhouse gas emission allowance trading within the Community. The latest amendment by Directive 2009/29/EC set the course for the time beyond the Kyoto Protocol period, originally based on the assumption that a global and comprehensive post-2012 agreement would be concluded in due time. The EU ETS is based on the cap-and-trade principle and offers tools to facilitate the achievement of climate targets without spoiling the economic scope of action. Firstly, by means of setting an emission cap, a price is put on carbon, which, secondly, enables trading GHG emission allowances on the carbon market at lowest cost.

Given the overall cap and using a downstream approach, the central EU authority, the EU Commission, has specified the trading sectors of the economy where emission allowances are traded: iron and steel, cement, glass, ceramics, pulp and paper, as well as the power sector. These sectors account for around 50\% of the EU emissions of carbon dioxide $\left(\mathrm{CO}_{2}\right)$ and for $40 \%$ of the EU's overall greenhouse gas emissions. Because $50 \%$ of the $\mathrm{CO}_{2} \mathrm{EU}$ emissions remain outside the trading program, the EU's Kyoto cap has to be met by an effort-sharing arrangement between sources in the trading and non-trading sectors. Industries that are not covered by the scheme, such as the private sector, transport, or the building industry, have to be regulated by other (national) abatement measures in order to reach each national emission reduction target. The EU ETS established three commitment periods for the time up to 2020. The first trading period (2005-2007) was actually seen as a test run and a learning phase to find out how the different actors involved in emissions trading react to the new system. The second phase (2008-2012) corresponded to the Kyoto commitment period. Within these two trading periods, the Member States endowed domestic covered sectors via the so-called National Allocation Plans (NAPs) with emissions allowances, which were subject to oversight from the European Commission. As far as the ETS sectors are concerned, the EU has learned important lessons for its third trading period (2013-2020) regarding the system's economic efficiency and ecological effectiveness. Hence, cap settings as well as harmonised allocation rules are determined directly at the EU level pursuant to the revised ETS directive. Further, within the revision and the preparation for a post-Kyoto period of the EU ETS, one central point was the intensification of auctioning allowances from 2013.

\section{Economic literature on the efficiency of the EU ETS}

In general, econometric literature on carbon pricing via emissions trading and especially the prices generated through the EU ETS is growing. Analyses show that daily spot prices generated by the EU ETS depend on institutional design issues, energy prices and extreme weather events [1]. The approach by Chevallier explains that $\mathrm{CO}_{2}$ future prices of the EU ETS are only weakly connected to macroeconomic effects [2]. In a different model of Creti et al. the oil price, the equity price index and the switching price between gas and coal seem to be significant long-run determinants of the $\mathrm{EU} \mathrm{CO}_{2}$ future price during the second phase of the EU ETS [3]. Further, the decisions of the second NAPs have crucial and direct influences on the EU ETS future prices [4].

Regarding the analysis of informational efficiency of the EU ETS until 2010, Aatola et al. find that the EU ETS market showed periods with no informational efficiency $[5,6]$. It is shown by Daskalakis and Markellos that three of the most important spot and future markets for EU ETS $\mathrm{CO}_{2}$ allowances deviate from the weak form of market efficiency [7]. Joyeux and Milunovich [8] do not detect informational efficiency in the EU ETS market 
in the first trading period while Hintermann [9] discovers inefficiency in the EU ETS before the price crash in 2006. In contrast to that, phases of informational efficiency within the first trading period have been noted. Seifert et al. use a stochastic optimal control model and show that $\mathrm{CO}_{2}$ prices do not follow seasonal patterns and that the EU ETS market worked informationally efficient [10]. Boutaba presents evidence that the EU ETS, among different carbon markets, showed a reasonable degree of efficiency in the short and long term [11]. Regarding a wider timeframe until spring 2009, Montagnoli and de Vries [12] observe the weak form of informational efficiency in the second phase of the EU ETS. Krishnamurti and Hoque [13] identify informational efficiency in the EU ETS $\mathrm{CO}_{2}$ option prices and that short maturity options are priced more efficiently than distant maturity options in the first half of the second trading period. In contrast to the stated literature, the present approach covers the whole of the first two trading periods, giving a wider base to the analysis which allows for a more accurate assement of informational efficiency in the EU ETS.

\section{EFFICIENT MARKET HYPOTHESIS AND RANDOM WALK THEORY}

The efficient market hypothesis (EHM), also known as the concept of informational efficiency or capital market efficiency derived by Fama, is an economic theory which deals with the information processing in capital markets [14]. A market is efficient if "security prices at any time "fully reflect" all available information" which means that all information is already factored in the actual price and hence, the realization of excess returns via forecasting methods is not possible [14]. This implies that in an informationally-efficient market not just present and historical data but also anticipated developments are taken into account within the price formation process. Shifting the focus to the EU ETS, this implies that market participants are aware of the relevant $\mathrm{CO}_{2}$ price data and the $\mathrm{CO}_{2}$ price data generating processes. In the case of new information, the market participants re-evaluate the shareholder values which lead to new $\mathrm{CO}_{2}$ price levels. As information is only classified to be new in case of non-anticipation of the market participant, shocks which directly affect the investment behaviour or the data generating processes can influence the price level.

Three diverse categories of information which yield three forms of the EHM can be identified [14]. Strong informational efficiency implies that the $\mathrm{CO}_{2}$ price reflects all available information. This assumption yields that publicly available and non-publicly available information (e.g. executive board development, mergers) is factored into the price analysis. The category of semi-strong informational efficiency advocates that actual $\mathrm{CO}_{2}$ price levels fully reflect information which is publicly available. Hence, all historical and fundamental data (e.g. economy, weather, fossil fuel prices) is integrated into the price signal. Therefore, only the usage of non-publicly available information or inside information allows for the generation of above-average returns. Event studies measuring the velocity of price changes due to new information can be applied to test this form of market efficiency. Finally, the weak form of the EHM proclaims that the actual price fully includes information of historical prices and returns which do not have any influence in future price developments. This suggests that regarding the weak informational efficiency of the EU ETS an analysis of past $\mathrm{CO}_{2}$ price behaviour as done by technical analysis does not lead to the generation of above-average returns. Only the availability of additional information allows generating higher returns. This form of efficiency is tested via analysis of the predictability of future returns with historical price data, as is done in this paper. The test of the weak form of informational efficiency implies that impacts of other variables than historic price levels on the $\mathrm{CO}_{2}$ price are disregarded. If effects of other variables are not directly reflected in the actual price level 
but rather influence the price level step by step, market participants will be informed about smaller rises about to come. Therefore, the reason for the change of the $\mathrm{CO}_{2}$ price change is unnecessary within this framework as the question is if and to what extend past price changes are informative for future price changes.

The weak-form of the EHM is linked to the statistical concept of a random walk, which states that all subsequent price changes symbolize random deviations from earlier prices. The random walk hypothesis assumes that the flow of information is unrestricted and information is directly integrated into market prices meaning that future prices will be independent of present price changes. Newly arriving information cannot be predicted which leads to the consequence that price changes are unpredictable and random. A random walk is defined as a stochastic process in the form of an autoregressive process, $p_{t}$ $=p_{t-1}+\beta+\varepsilon_{t}$, where $p_{t}$ symbolizes the natural logarithm of the EUA price at point of time $t, \beta$ denotes a drift parameter and $\varepsilon_{t}$ represents the random increment and is independent and identically distributed with mean zero and variance $\sigma^{2}$. The random term can be interpreted as the effect of arriving information on the actual $\mathrm{CO}_{2}$ price. The first difference is displayed via $\Delta p_{t}=\beta+\varepsilon_{t}$. Further, this model states that the expected value of the $\mathrm{CO}_{2}$ price is identical to the expected value in the previous periods adjusted to the unanticipated information.

\section{ANALYSIS OF INFORMATIONAL EFFCICENCY OF THE EU ETS}

In the following, the underlying statistical methodology for random walk testing and the examined data set are presented.

\section{Statistical methodology}

According to former approaches $[6,15]$ the focus is laid on analysing random walks which are characterised by dependent and not identically distributed random increments. Thus, the empirical methodology to investigate the informational efficiency contains unit root tests, analysis of autocorrelation and variance ratio tests.

Unit root tests. Unit root tests are used to examine whether a time series represents a non-stationary stochastic process. As a random walk is a first difference stationary process, $\mathrm{CO}_{2}$ prices generated by the EU ETS need to contain a unit root while the first difference of the series does not. The Augmented Dickey-Fuller Test (ADF) is an augmented form of the Dickey-Fuller Test (DF) [16] which responds to larger and more complex time series models. It extends the framework of the DF in the sense of assuming that $p_{t}$ follows an autoregressive process of order $k$ with $\mathrm{c}$ denoting a constant and $k>1$ :

$$
p_{t}=\mathrm{c}+\delta_{t} p_{t-1}+\ldots+\delta_{k} p_{t-k}+\varepsilon_{t}
$$

This process is equal to:

$$
\Delta p_{t}=\mathrm{c}+\theta p_{t-1}+\beta_{1} \Delta p_{t-1}+\ldots+\beta_{k-1} \Delta p_{t-(k-1)}+\varepsilon_{t}
$$

where $\theta:=\delta_{1}+\ldots+\delta_{k-1} . \theta<0$ holds for a stationary process while $\theta=0 \Leftrightarrow \delta:=\sum \delta_{i}=$ 1 indicates a non-stationary process. Hence, the null hypothesis which says that $p_{t}$ is non-stationary and contains a unit root is given by:

$$
H_{0}: \theta=0
$$


The alternative hypothesis stating that $p_{t}$ is a stationary process is represented by:

$$
H_{1}: \theta<0
$$

The ADF requires homoskedastic and independent error terms $\varepsilon_{t}$. Regarding the choice of the lag-length of the autoregressive model, it should be chosen sufficiently large in order to avoid misspecification of the model. On the contrary, a too generous $k$ may lead to the fact that the null hypothesis is not rejected. In practice, $k$ should be set in the way that a defined criterion of information which allows comparing the validity of nested models is fulfilled. In this case, the Akaike-Information criterion (AIC) is applied.

A further approach to test for unit roots is given by the Phillips-Perron Test (PP) [17]. The PP adjusts for serial correlation and heteroskedasticity in the errors terms non-parametrically by adapting the DF test statistics. Therefore, these test statistics can be interpreted as DF test statistics adaptive to serial correlation by applying the Newey-West heteroskedasticity - and autocorrelation-consistent covariance matrix estimator. Besides the advantage of allowing for heteroskedasticity in the error term, the further benefit is that no lag length for the test regression has to be specified compared to the ADF.

Finally, the methodology of the Kwiatkowski-Phillips-Schmidt-Shin Test (KPSS) [18] is also applied within the testing for unit roots. In contrast to the procedures of the ADF and the PP, the KPSS proposes stationarity as the null hypothesis and non-stationarity as the alternative hypothesis. The time series is modelled as the sum of a deterministic trend, a random walk and a white noise whereas the KPSS tests if the random walk has a zero variation using specific critical values.

Autocorrelation coefficients. In order to state if the $\mathrm{CO}_{2}$ price series follows as a random walk the next step contains an autocorrelation analysis. Autocorrelation of a series regarding the $k$-th lag refers to the correlation between the lags $p_{t}$ and $p_{t-k}$. Regarding the random walk model with dependent and not identically distributed random increments, all autocorrelation coefficients between $\Delta p_{t}$ and $\Delta p_{t-k}$ need to equal zero for all $k>0$. Hence, the $k$-th autocorrelation coefficient, $\rho(k)$, can be described as:

$$
\rho(k)=\frac{\operatorname{cov}\left(p_{t}-p_{t-k}\right)}{\sqrt{\operatorname{var}\left(p_{t}\right) \operatorname{var}\left(p_{t-k}\right)}}
$$

In the case of serial autocorrelation, an autoregressive model of order $j$ displays $p_{t}$ as a linear function of the lagged variables $p_{t-1}, \ldots, p_{t-j}$. Autocorrelation coefficients going to zero continuously with a growing $k$ indicate autoregressive properties of the process whereas an abrupt reduction of the coefficients to zero in case of a growing $k$ represents a moving-average process. The application of the Ljung-Box $Q$-statistic at lag $k$ allows for testing the null hypothesis that there is no autocorrelation up to order $k$ and the significance of the autocorrelation coefficients, respectively.

Variance ratio tests. As stated in the previous subsection, the autocorrelation $\rho(k)$ between $\Delta p_{t}$ and $\Delta p_{t-k}$ needs to equal zero for all $k>0$ in order to fulfil the requirements of a random walk with dependent and not identically distributed random increments. The variance ratio test indicates if the variance of the random walk's error term is a linear function of time. The variance ratio derived by Lo and MacKinlay [19] is defined as: 


$$
V R(q)=\frac{\operatorname{var}\left(\Delta p_{t}(q)\right)}{q \operatorname{var}\left(\Delta p_{t}\right)}=1+2 \sum_{k=1}^{q-1}\left(1-\frac{k}{q}\right) \rho(k)
$$

The standardized test statistic $\psi$ investigates the independence of the error terms of the process. It is defined as:

$$
\psi=\frac{\sqrt{T-1}(V R(q)-1)}{\sqrt{\hat{\theta}}} \sim N(0,1)
$$

$\theta$ represents a heteroscedasticity-consistent estimator of the variance of $V R(q)$.

\section{Sample structure and data transformation}

In order to study the behaviour of the EUA prices, daily settlement price data from August 2005 to June 2012 is analysed which leads to 1,468 observations. The data is based on price information provided by the European Energy Exchange (EEX). Structuring the data with regard to the first and second trading phases, the sample of the first trading phase includes 607 observations from August 2005 to December 2007 while the sample of the second trading phase includes 861 observations from January 2009 to June 2012. Due to missing data on the settlement prices from March 2008 to December 2008, the sample of the EUA price for the second trading phase disregards data for 2008. Figure 1 displays the price levels in the different trading phases.

As already mentioned in the introductory section, overallocation due to strategic allowance endowment to domestic EU ETS sectors by governments led to the abrupt price drop in spring 2006 [1]. Until April 2007, the EUA price almost arrived at $€ 0.1$ per ton $\mathrm{CO}_{2}$. In the second trading period (2008-2012), less volatile price behaviour is observed. Stricter revision of the NAP and, consequently, more stringent cap setting by the EU Commission led to an average spot price of $€ 14$ per ton $\mathrm{CO}_{2}$ in 2009 and 2010, $€ 13$ per ton $\mathrm{CO}_{2}$ in 2011 and $€ 7$ per ton $\mathrm{CO}_{2}$ in 2012. Regarding this second trading phase, economic recession inducing lower production activities by the covered sectors and unsuccessful climate policy negotiations may have generated low EUA price levels.

In the present analysis, EUA prices at point of time $t$ are denoted by $P_{t}$ and are examined via its natural logarithm series, $p_{t}=\ln \left(P_{t}\right)$, and the differentiated natural logarithm series, $\Delta p_{t}=p_{t}-p_{t-1}$, displaying proportional deviations of the original price series. Hence, $\Delta p_{t}$ expresses the logarithmic EUA price returns at point $t$. Figures 2 and 3 show the price history of $p_{t}$ and $\Delta p_{t}$ while the series' descriptive statistics are presented in Table 1.

Table 1. Descriptive statistics for $p_{t}$ and $\Delta p_{t}$

\begin{tabular}{ccccc}
\hline & \multicolumn{2}{c}{$p_{t}$} & \multicolumn{2}{c}{$\Delta p_{t}$} \\
\hline Trading period & $2005-2007$ & $2009-2012$ & $2005-2007$ & $2009-2012$ \\
\hline Mean & 1.408 & 2.508 & -0.011 & 0.007 \\
Variance & 5.735 & 0.070 & 0.010 & 0.049 \\
Kurtosis & 1.881 & 3.270 & 34.245 & 833,832 \\
Skewness & -0.714 & 1.200 & 1.346 & 28.644 \\
Observations & 607 & 861 & 606 & 860 \\
\hline
\end{tabular}




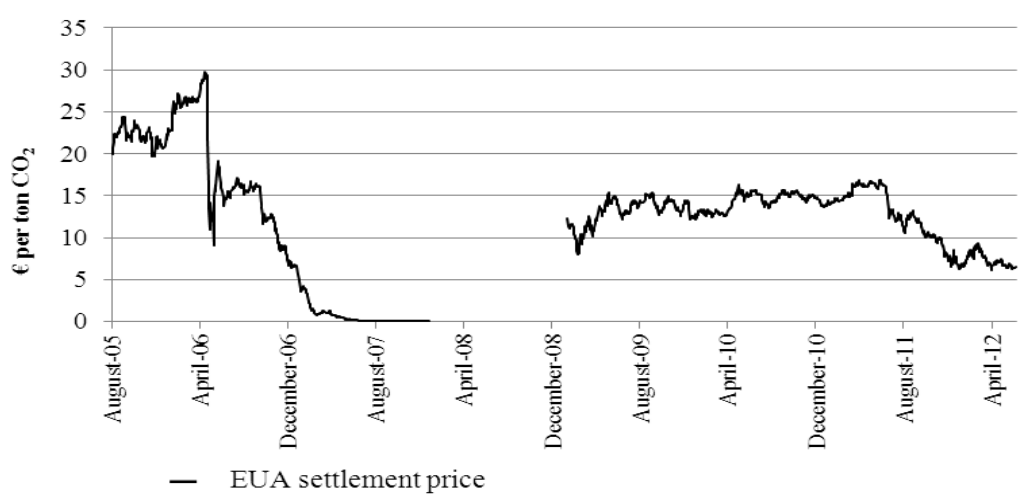

Figure 1. EUA settlement prices in the EU ETS

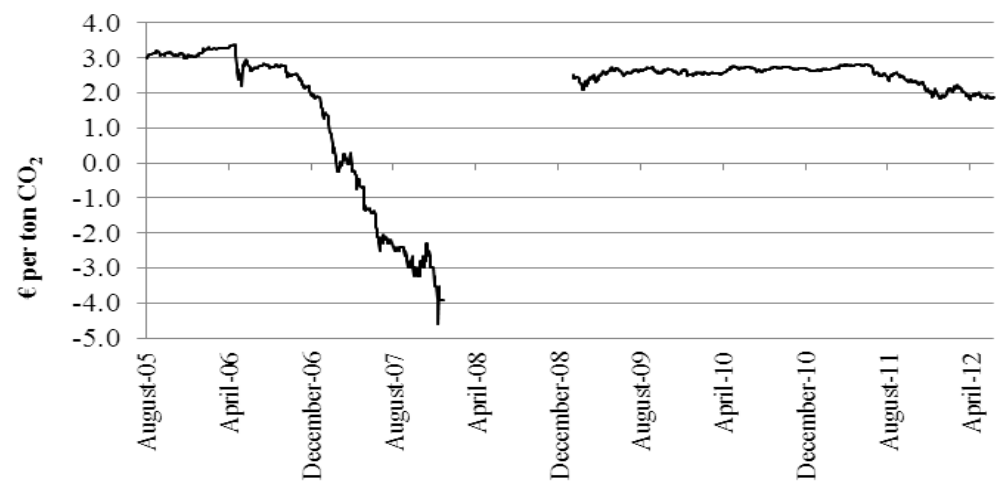

- Natural logarithm of EUA settlement price

Figure 2. Natural logarithm of EUA settlement prices in the EU ETS

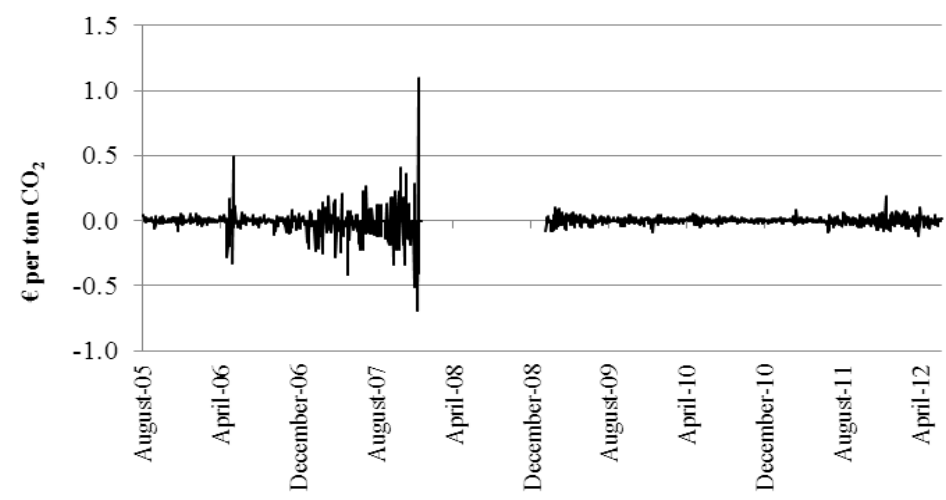

- Differentiated natural logarithm of EUA settlement price

Figure 3. Differentiated natural logarithm of EUA settlement prices in the EU ETS

\section{RESULTS}

Based on the described statistical methodology this section presents the results and offers an interpretation regarding the scheme's level of informational efficiency in the focused timeframes. As explained above, unit root tests are used to examine whether a time series represents a non-stationary stochastic process. The presence of a unit root is interpreted as the null hypothesis. As random walks are first difference stationary processes, if $p_{t}$ contains a unit root it is non-stationary, while if $\Delta p_{t}$ does not contain a unit 
root it is stationary. As Table 2 reports, the performed unit root tests indicate at $10 \%, 5 \%$ and $1 \%$ significance levels non-stationarity for $p_{t}$ and stationarity for $\Delta p_{t}$ regarding the first trading period (2005-2007). Considering the second trading phase (2009-2012), only the ADF-test ignoring a constant and a trend does not reject the null of non-stationarity for $p_{t}$ at a $10 \%$ significance level. On the contrary, the KPSS-tests reject clearly stationarity for $p_{t}$ at all significance levels. Analogously to the first trading phase, the unit root tests reveal stationarity for $\Delta p_{t}$ at all significance levels. Hence, the results point out that $\mathrm{CO}_{2}$ prices generated by the EU ETS may have followed a random walk during the first two trading periods whereas the findings for the first trading period show stronger evidence.

Table 2. Unit root tests for $p_{t}$ and $\Delta p_{t}$

\begin{tabular}{lllll}
\hline & \multicolumn{2}{c}{ Test statistics for $p_{t}$} & \multicolumn{2}{c}{ Test statistics $\Delta p_{t}$} \\
\hline \multicolumn{1}{c}{ Test } & $2005-2007$ & $2009-2012$ & $2005-2007$ & $2009-2012$ \\
\hline ADF (constant) & 1.49 & $-23.55^{* * * *}$ & $-4.00^{* * * *}$ & $-10.40^{* * * *}$ \\
ADF (constant+trend) & -1.64 & $-30.89^{* * * *}$ & $-4.66^{* * * *}$ & $-10.60^{* * * *}$ \\
ADF & $-0,20$ & $-1.60^{*}$ & $-2.88^{* * *}$ & $-10.36^{* * * *}$ \\
PP (constant) & 1.61 & $-27.67^{* * * *}$ & $-30.03^{* * *}$ & $-29.70^{* * *}$ \\
PP (constant+trend) & -1.66 & $-30.01^{* * * *}$ & $-30.16^{* * * *}$ & $-29.80^{* * * *}$ \\
PP & 0.12 & $-1.64^{* * * *}$ & $-29.14^{* * * *}$ & $-29.67^{* * * *}$ \\
KPSS (constant) & $2.96^{* * *}$ & $1.47^{* * *}$ & 0.65 & 0.38 \\
KPSS (constant+trend) & $0.76^{* * *}$ & $0.72^{* * *}$ & 0.07 & 0.12 \\
\hline ****and *** refer to significance at the 10\%, 5\% and 1\% levels. & & \\
Regarding the ADF-tests, the number of lags is specified via the AIC. &
\end{tabular}

In order to adopt the random walk hypothesis, autocorrelation between $\Delta p_{t}$ and $\Delta p_{t-k}$ for all $k>0$ needs to equal zero. The results of the autocorrelation analysis as well as their significance indicated by the Ljung-Box $Q(k)$-statistic are presented in Table 3. With respect to the autocorrelation of $p_{t}$ in the first and the second trading period, strong positive autocorrelation can be observed by gradually decreasing coefficients with increasing number of lags. Studying the autocorrelation of $\Delta p_{t}$ within the first trading period (2005-2007) leads to the conclusion that the null hypothesis of no autocorrelation has to be rejected at all significance levels. Regarding the second trading period (2009-2012), autocorrelation coefficients near to zero and low Ljung-Box $Q(k)$-statistics reveal that lagged change in the logarithmic $\mathrm{CO}_{2}$ price does not explain the current change. As a conclusion, the requirements that the EUA price followed a random walk are only fulfilled in the second trading period (2009-2012).

Finally, variance ratio tests are applied in order to study the EUA price series' incremental behaviours. Following the random walk hypothesis, the increments need to follow a linear function of time. This means that the $q$-period difference should be q times the variance of the one-period difference. The results in Table 4 display that random walk properties are not satisfied in the first trading period (2005-2007). The null of a random walk can be rejected for all $q \leq 7$ at all significance levels. Nevertheless, for $q>10$ the test fails to reject the null of no significant autocorrelation among the returns. Focusing the second trading period (2009-2012), values of $V R(q)$ are near to one until $q=10$ and throughout we fail to reject the null of autocorrelation, indicating the presence of a random walk. Hence, the variance ratio tests support the findings of the former autocorrelation analysis which found random walk behaviour in $\mathrm{CO}_{2}$ prices for the second trading period. 
Table 3. Autocorrelations for $p_{t}$ and $\Delta p_{t}$

\begin{tabular}{|c|c|c|c|c|}
\hline & \multicolumn{2}{|c|}{$p_{t}$ in $2005-2007$} & \multicolumn{2}{|c|}{$\Delta p_{t}$ in 2005-2007 } \\
\hline Lag $k$ & Autocorrelation & $Q(k)$ & Autocorrelation & $Q(k)$ \\
\hline 1 & 0.995 & $604.0^{* * * *}$ & -0.194 & $22.87^{\text {***** }}$ \\
\hline 2 & 0.990 & $1,203.2^{* * * *}$ & 0.010 & $22.93^{\text {*** }}$ \\
\hline 3 & 0.986 & $1,797.8^{* * * *}$ & 0.035 & $23.69^{* * *}$ \\
\hline 4 & 0.981 & $2,387.5^{* * * *}$ & -0.084 & $28.10^{* * *}$ \\
\hline 5 & 0.976 & $2,972.5^{* * *}$ & 0.085 & $32.44^{* * *}$ \\
\hline 6 & 0.971 & $3,552.6^{* * * *}$ & 0.054 & $34.23^{* * *}$ \\
\hline 7 & 0.967 & $4,128.4^{* * * *}$ & 0.084 & $38.52^{\text {*** }}$ \\
\hline 8 & 0.961 & $4,697.9^{* * * *}$ & -0.119 & $47.32^{* * *}$ \\
\hline 9 & 0.956 & $5,262.4^{* * *}$ & 0.098 & $53.30^{* * *}$ \\
\hline 10 & 0.950 & $5,821.7^{* * * *}$ & -0.114 & $61.28^{* * *}$ \\
\hline 11 & 0.945 & $6,376.0^{* * * *}$ & 0.028 & $61.78^{* * *}$ \\
\hline 12 & 0.941 & $6,926.0^{* * * *}$ & 0.093 & $67.17^{* * *}$ \\
\hline 13 & 0.936 & $7,471.4^{* * * *}$ & -0.055 & $69.04^{* * *}$ \\
\hline 14 & 0.932 & $8,012.4^{* * *}$ & -0.054 & $70.29^{* * *}$ \\
\hline 15 & 0.927 & $8,549.0^{* * *}$ & 0.048 & $71.74^{* * *}$ \\
\hline 16 & 0.923 & $9,081.5^{* * *}$ & -0.060 & $73.98^{* * *}$ \\
\hline 17 & 0.918 & $9,609.7^{* * *}$ & -0.011 & $74.06^{* * *}$ \\
\hline 18 & 0.914 & $10,134^{* * * *}$ & 0.088 & $78.87^{\text {*** }}$ \\
\hline 19 & 0.910 & $10,655^{* * *}$ & -0.025 & $79.26^{* * *}$ \\
\hline \multirow[t]{2}{*}{20} & 0.906 & $11,172^{* * * *}$ & -0.061 & $81.59^{* * *}$ \\
\hline & \multicolumn{2}{|c|}{$p_{t}$ in 2009-2012 } & \multicolumn{2}{|c|}{$\Delta p_{t}$ in 2009-2012 } \\
\hline Lag $k$ & Autocorrelation & $Q(k)$ & Autocorrelation & $Q(k)$ \\
\hline 1 & 0.992 & $849.54^{* * * *}$ & -0.012 & 0.12 \\
\hline 2 & 0.982 & $1,684.5^{* * *}$ & -0.005 & 0.14 \\
\hline 3 & 0.974 & $2,506.0^{* * * *}$ & 0.001 & 0.14 \\
\hline 4 & 0.965 & $3,313.9^{* * * *}$ & 0.005 & 0.16 \\
\hline 5 & 0.957 & $4,108.1^{* * * *}$ & -0.002 & 0.17 \\
\hline 6 & 0.948 & $4,889.3^{* * * *}$ & 0.004 & 0.18 \\
\hline 7 & 0.940 & $5,658.7^{* * *}$ & -0.000 & 0.18 \\
\hline 8 & 0.932 & $6,414.9^{* * *}$ & -0.000 & 0.18 \\
\hline 9 & 0.923 & $7,157.7^{* * *}$ & 0.001 & 0.18 \\
\hline 10 & 0.915 & $7,888.1^{* * * *}$ & -0.001 & 0.18 \\
\hline 11 & 0.907 & $8,607.2^{* * * *}$ & -0.005 & 0.20 \\
\hline 12 & 0.900 & $9,315.3^{* * * *}$ & -0.013 & 0.35 \\
\hline 13 & 0.893 & $10,014^{* * *}$ & -0.002 & 0.35 \\
\hline 14 & 0.885 & $10,701^{* * *}$ & -0.003 & 0.36 \\
\hline 15 & 0.877 & $11,377^{* * * *}$ & -0.002 & 0.36 \\
\hline 16 & 0.869 & $12,041^{* * * *}$ & -0.000 & 0.36 \\
\hline 17 & 0.861 & $12,694^{* * * *}$ & -0.001 & 0.46 \\
\hline 18 & 0.852 & $13,333^{* * *}$ & -0.012 & 0.58 \\
\hline 19 & 0.844 & $13,962^{* * * *}$ & -0.009 & 0.66 \\
\hline 20 & 0.837 & $14,580^{* * * *}$ & 0.007 & 0.71 \\
\hline
\end{tabular}

$* * *$ and $* * *$ refer to significance at the $10 \%, 5 \%$ and $1 \%$ levels. 
Table 4. Variance ratio test for $\Delta p_{t}$

\begin{tabular}{lllll}
\hline & \multicolumn{2}{c}{$2005-2007$} & \multicolumn{2}{c}{$2009-2012$} \\
\hline$q$ & $V R(q)$ & $\Psi(q)$ & $V R(q)$ & $\Psi(q)$ \\
\hline 2 & 0.860 & $-4.777^{* * * * *}$ & 0.987 & -0.374 \\
3 & 0.747 & $-4.171^{* * * *}$ & 0.979 & -0.415 \\
4 & 0.735 & $-3.481^{* * * *}$ & 0.975 & -0.394 \\
5 & 0.695 & $-3.432^{* * * *}$ & 0.974 & -0.351 \\
6 & 0.695 & $-3.034^{* * *}$ & 0.972 & -0.332 \\
7 & 0.709 & $-2.632^{* * * *}$ & 0.955 & -0.490 \\
8 & 0.730 & $-2.250^{* *}$ & 0.984 & -0.159 \\
9 & 0.730 & $-2.094^{* *}$ & 0.981 & -0.172 \\
10 & 0.750 & $-1.824^{*}$ & 0.980 & -0.178 \\
20 & 0.751 & -1.232 & 0.863 & -0.809 \\
\hline
\end{tabular}

$* * *$ and $* * *$ refer to significance at the $10 \%, 5 \%$ and $1 \%$ levels.

\section{CONCLUSION}

The concept of informational efficiency proclaims that the market price should include all available information at any time. Firms subject to the EU ETS face uncertainty regarding their investment and production activities which suggests that competitive disadvantages may occur in relation to firms which are not regulated or face credible $\mathrm{CO}_{2}$ signals. Hence, the inexistence of informational efficiency constrains the object of cost-efficiency which requires that emissions abatement is achieved at lowest costs. The focus is drawn on the weak form of informational efficiency which suggests that price fully includes information of historical prices and returns which do not have any influence in future price developments.

By applying unit root, autocorrelation and variance ratio tests, evidence is derived that within the first trading period the EU ETS did not operate with informational efficiency whereas it did in the second trading period. This implicates that within the second trading period market participants had a better understanding of the $\mathrm{CO}_{2}$ price generating processes and the way in which information affects the equilibrium $\mathrm{CO}_{2}$ price. Compared to existing literature on the informational efficiency of the EU ETS, these findings support past findings of no informational inefficiency within the first trading period of Dsakalakis and Markellos [7], Hintermann [9], Joyeux and Milunovich [8], Montagnoli and de Vries [12]. Further, as the analysis covers the complete second trading period, the findings add the first evidence of informational efficiency in first parts of the second trading period achieved by Montagnoli and de Vries [12]. Further research from a financial economics point of view regarding the scheme's informational efficiency within the third trading period will be necessary to state if the EU ETS is on a continuous path to better efficiency via the regulatory changes of 2013 which included, centralised cap setting and a harmonisation of allocation rules.

\section{ACKNOWLEDGEMENTS}

I would like to thank the editor, three anonymous reviewers and Friedrich Schneider for their valuable comments on previous versions of this article. Further, the support of this work by the Energy Institute at the Johannes Kepler University of Linz is gratefully acknowledged. 


\section{NOMENCLATURE}

c constant

$k \quad$ order of process, lag

$P \quad$ European $\mathrm{CO}_{2}$ price

$p \quad$ natural logarithm of European $\mathrm{CO}_{2}$ price

$q \quad$ period

$V R \quad$ variance ratio

\section{Greek letter}

$\beta \quad$ drift parameter

$\Delta \quad$ first difference

$\varepsilon \quad$ error term

$\sigma \quad$ variance

$\rho \quad$ autocorrelation coefficient

$\Psi \quad$ standardized test statistic

\section{Subscript}

$t \quad$ point of time
$[-]$

$[-]$

$[-]$

$[-]$

$[-]$

$[-]$

\section{Abbreviations}

$\begin{array}{ll}\text { ADF } & \text { Augmented Dickey-Fuller Test } \\ \text { AIC } & \text { Akaike-Information Criterion } \\ \mathrm{CO}_{2} & \text { Carbon Dioxide } \\ \text { DF } & \text { Dickey-Fuller Test } \\ \text { EEX } & \text { European Energy Exchange } \\ \text { EHM } & \text { Efficient Market Hypothesis } \\ \text { EU } & \text { European Union } \\ \text { EUA } & \text { European Allowance } \\ \text { EU ETS } & \text { European Emissions Trading Scheme } \\ \text { KPSS } & \text { Kwiatkowski-Phillips-Schmidt-Shin Test } \\ \text { NAP } & \text { National Allocation Plan } \\ \text { PP } & \text { Phillips-Perron Test }\end{array}$

\section{REFERENCES}

1. Alberola, E., Chevallier, J. and Cheze, B., Price Drivers and Structural breaks in European Carbon Prices 2005-2007, Energy Policy, Vol. 36, No. 2, pp 787-79, 2008, http://dx.doi.org/10.1016/j.enpol.2007.10.029

2. Chevallier, J., Carbon Futures and Macroeconomic Risk Factors: A view from the EU ETS, Energy Economics, Vol. 31, No. 4, pp 614-625, 2009, http://dx.doi.org/10.1016/j.eneco.2009.02.008

3. Creti, A., Jouvet, P. and Mignon, V., Carbon Price Drivers: Phase I versus Phase II Equilibrium? Energy Economics, Vol. 34, No. 1, pp 327-334, 2012, http://dx.doi.org/10.1016/j.eneco.2011.11.001

4. Conrad, C., Rittler, D. and Rotfuss, W., Modeling and Explaining the Dynamics of European Union Allowance Prices at High-frequency, Energy Economics, Vol. 34, No. 1, pp 316-326, 2012, http://dx.doi.org/10.1016/j.eneco.2011.02.011

5. Aatola, P., Ollikka, K. and Ollikainen, M., Weak and Semi-Strong Forms of Informational Efficiency in the EU ETS Markets, Discussion Papers no 48, University of Helsinki, Department of Economics and Management, Helsinki, 2010. 
6. Aatola, P., Ollikka, K. and Ollikainen, M., Informational Efficiency of the EU ETS Market-a Study of Price predictability and Profitable trading, Working Papers no 28, Government Institute for Economic Research, Helsinki, 2012.

7. Daskalakis, G. and Markellos, R., Are the European Carbon Markets Efficient? Review of Futures Markets, Vol. 17, No. 2, pp 103-128, 2008.

8. Joyeux, R. and Milunovich, G., Market Efficiency and Price Discovery in the EU Carbon Futures Market, Applied Financial Economics, Vol. 20, No. 10, pp 803-809, 2010, http://dx.doi.org/10.1080/09603101003636220

9. Hintermann, B., Allowance Price drivers in the First Phase of the EU ETS, Journal of Environmental Economics and Management, Vol. 59, No. 1, pp 43-56, 2010, http://dx.doi.org/10.1016/j.jeem.2009.07.002

10.Seifert, J., Uhrig-Homburg, M. and Wagner, M., Dynamic Behavior of CO2 Spot Prices, Journal of Environmental Economics and Management, Vol. 56, No. 2, pp 180-194, 2008, http://dx.doi.org/10.1016/j.jeem.2008.03.003

11.Boutaba, M., Dynamic Linkages among European Carbon Markets, Economics Bulletin, Vol. 29, No. 2, pp 499-511, 2008.

12.Montagnoli, A. and de Vries, F., Carbon Trading Thickness and Market Efficiency, Energy Economics, Vol. 32, No. 6, pp 1331-1336, 2010, http://dx.doi.org/10.1016/j.eneco.2010.04.001

13.Krishnamurti, C. and Hoque, A., Efficiency of European Emissions Markets: Lessons and Implications, Energy Policy, Vol. 39, No. 10, pp 6575-6582, 2011, http://dx.doi.org/10.1016/j.enpol.2011.07.062

14.Fama, E., Efficient Capital Markets: A review of Theory and Empirical Work, Journal of Finance, Vol. 25, No. 2, pp 383-417, 1970, http://dx.doi.org/10.2307/2325486

15.Albrecht, J., Verbeke, T. and De Clerq, M., Informational Efficiency of the US $\mathrm{SO}_{2}$ Market, Environmental Modeling and Software, Vol. 21, No. 10, pp 1471-1478, 2006, http://dx.doi.org/10.1016/j.envsoft.2005.07.006

16.Dickey, D. and Fuller, W. Distribution of the Estimators for Autoregressive Time Series With a Unit Root, Journal of the American Statistical Association, Vol. 74, pp 427-431, 1976, http://dx.doi.org/10.1080/01621459.1979.10482531

17.Philips, P. and Perron, P., Testing for a Unit Root in Time Series Regression, Biometrika, Vol. 75, No. 2, pp 335-346, 1988, http://dx.doi.org/10.1093/biomet/75.2.335

18.Kwiatkowski, D., Phillips, P., Schmidt, P. and Shin, Y., Testing the Null Hypothesis of Stationarity against the Alternative of a Unit Root, Journal of Econometrics, Vol. 54, No. 1-3, pp 159-178, 1992, http://dx.doi.org/10.1016/0304-4076(92)90104-Y

19.Lo, A. and MacKinlay, A., Stock Market Prices do not Follow Random walks: Evidence from a Simple Specification Test, The Review of Financial Studies, Vol. 1, No. 1, 41-66, 1988, http://dx.doi.org/10.1093/rfs/1.1.41

Paper submitted: 30.01 .2014

Paper revised: 27.05.2014

Paper accepted: 27.05.2014 